This item was submitted to Loughborough's Research Repository by the author.

Items in Figshare are protected by copyright, with all rights reserved, unless otherwise indicated.

\title{
Pursuing a response by repairing an indexical reference
}

PLEASE CITE THE PUBLISHED VERSION

http://dx.doi.org/10.1080/08351813.2012.673380

PUBLISHER

(C) Taylor \& Francis

VERSION

AM (Accepted Manuscript)

LICENCE

CC BY-NC-ND 4.0

REPOSITORY RECORD

Bolden, Galina B., Jenny Mandelbaum, and Susan J. Wilkinson. 2019. "Pursuing a Response by Repairing an Indexical Reference". figshare. https://hdl.handle.net/2134/15593. 
This item was submitted to Loughborough's Institutional Repository (https://dspace.lboro.ac.uk/) by the author and is made available under the following Creative Commons Licence conditions.

\section{creative
commons}

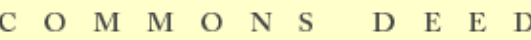

Attribution-NonCommercial-NoDerivs 2.5

You are free:

- to copy, distribute, display, and perform the work

Under the following conditions:

Attribution. You must attribute the work in the manner specified b the author or licensor.

Noncommercial. You may not use this work for commercial purposes.

No Derivative Works. You may not alter, transform, or build upon this work.

- For any reuse or distribution, you must make clear to others the license terms of this work.

- Any of these conditions can be waived if you get permission from the copyright holder.

Your fair use and other rights are in no way affected by the above.

This is a human-readable summary of the Leqal Code (the full license).

\section{Disclaimer 만}

For the full text of this licence, please go to: http://creativecommons.org/licenses/by-nc-nd/2.5/ 
Bolden, G.B., Mandelbaum, J. and Wilkinson, S. (2012) Pursuing a response by repairing an indexical reference. Research on Language and Social Interaction, 45(2): 137-155.

Running head: PURSUING A RESPONSE

Pursuing a Response by Repairing an Indexical Reference

Galina B. Bolden, Jenny Mandelbaum, Sue Wilkinson [alphabetical] 


\begin{abstract}
Prior conversation analytic research has demonstrated that when, following a sequence-initiating action, a response is relevantly missing (or delayed, or inadequate), speakers may use a range of practices for pursuing a response. These practices range from (relatively) overt to (relatively) covert and can either expose or mask the response pursuit and the problem it attempts to redress. This paper extends this prior research by demonstrating that speakers can also use repair technology - and specifically repair of an indexical expression - as a resource for pursuing a response covertly. Initiating repair on an indexical expression in transition space claims that a missing response is due to a problem of understanding a reference, and by repairing it, the speaker makes available another opportunity for a response, without making response pursuit the overt business of the talk. Likewise, initiating repair on an indexical expression in the third turn covertly treats the provided response as in some way inadequate, while avoiding going on record as doing so. We show that, by ostensibly dealing with problems of reference, repairs on indexicals manage other more interactionally-charged issues, such as upcoming disagreement or misalignment between interlocutors.
\end{abstract}

Key words: repair, response pursuit, indexical expressions 
Pursuing a response by repairing an indexical reference

This paper develops the theme of several other papers in this Special Issue that selfinitiated repair on indexical reference forms can be used to perform actions other than fixing problems of speaking, hearing and understanding. We have already seen that indexical repair can be used to adumbrate dispreference, express surprise, make a joke, and display the relevance of the categorical membership of the referent (revise list as needed, and cross-reference other papers in SI here). In this paper, we show that indexical repair can be used specifically to pursue a response.

In general, initiating actions (first pair parts in adjacency pair sequences) make responding relevant (Schegloff, 2007). Prior conversation analytic research (e.g., Davidson, 1984; Heritage, 1984; Jefferson, 1981; Pomerantz, 1984b; Schegloff, 2000; Stivers \& Rossano, 2010) has demonstrated that when, following a sequence-initiating action, a response is relevantly missing (or delayed, or inadequate), speakers may use a range of practices for pursuing a response. As Pomerantz (1984b) showed, pursuits may deal with the lack of (immediate) response as indicative of problems of reference, problems of understanding or knowledge, or of upcoming disagreement. As illustrated below (Extracts 1-5), a response may be pursued (relatively) overtly or (relatively) covertly and different conversational practices can either expose or mask the pursuit and the problem it attempts to redress.

In Extracts 1-3, speakers of initiating actions make use of sequence-organizational resources (Schegloff, 2007) in that they re-issue (a version of) the initiating action after the recipient has failed to produce a response. Extract 1 shows an overt pursuit of response in the face of no uptake. The first speaker (A) asks a question (the status enquiry "Is there something bothering you?", lines 1-2), but - despite the strong conditional relevance of an answer - this 
question is met with silence (at line 3). Speaker A then self-selects (Sacks, Schegloff, \& Jefferson, 1974) to pursue a response: first by reissuing the question in an elided form of two alternative candidate answers ("Yes or no", line 4), and then (when these are met with more silence), by producing a response prompt (“Eh?” in line 6). The recipient finally responds at line 7. In this instance, an initial turn is extended with two further whole turn constructional units (or TCUs Sacks et al., 1974) wholly dedicated to the task of pursuing a response. Furthermore, the speaker pursues a response in a way that exposes the absence of a relevant response and, quite explicitly, holds B accountable for producing an answer (see Heritage, 1984).

Extract 1: Heritage 1984 p. 248

$\begin{array}{lll}01 & \text { A: } & \text { Is there something bothering } \\ 02 & & \text { you? } \\ 03 & & (1.0) \\ 04 & \text { A: } & \text { Yes or no } \\ 05 & & (1.5) \\ 06 & \text { A: } & \text { Eh? } \\ 07 & \text { B: No. }\end{array}$

Extract 2 also shows response pursuit that relies on sequence-organizational resources, but in this case the pursuit does not expose the lack of a response as the addressee's problem (as in Extract 1). Rather, the response pursuit diagnoses the lack of (immediate) response as indicative of incipient disagreement. The inquiry at line 1 prefers an agreeing "yes" answer (Sacks, 1987; Schegloff, 2007). When there is no immediate response forthcoming, the first speaker (A) reformulates the question (in a whole new TCU) so as to reverse its preference, backing down from the expectation of an agreeing response (that there is a "good cook" there) and reversing his position ("nothing special"). By thus reformulating the inquiry, the speaker attributes the lack of a timely response to a problem of agreement.

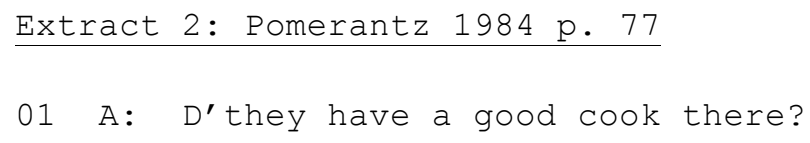




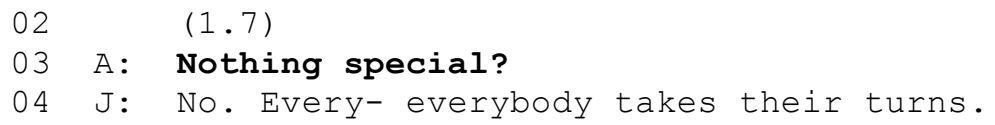

Extract 3 shows another instance of a speaker extending her turn in pursuit of a response by producing a whole new TCU. Here, however, the speaker reasserts her position in a way that simply re-relevances a response, without orienting to a possible problem a delay in responding might adumbrate. When Emma's assessment that "some of these kids need a good JO:B" is met with silence from Nancy (line 4), she self-selects to produce another TCU, proffering what is analyzably the same assessment (“Get ou:t'n: do a liddle wor:k", line $5^{\mathrm{i}}$ ) and re-relevancing a response from Nancy.

\section{Extract $3:[N B: I I: 2]$}

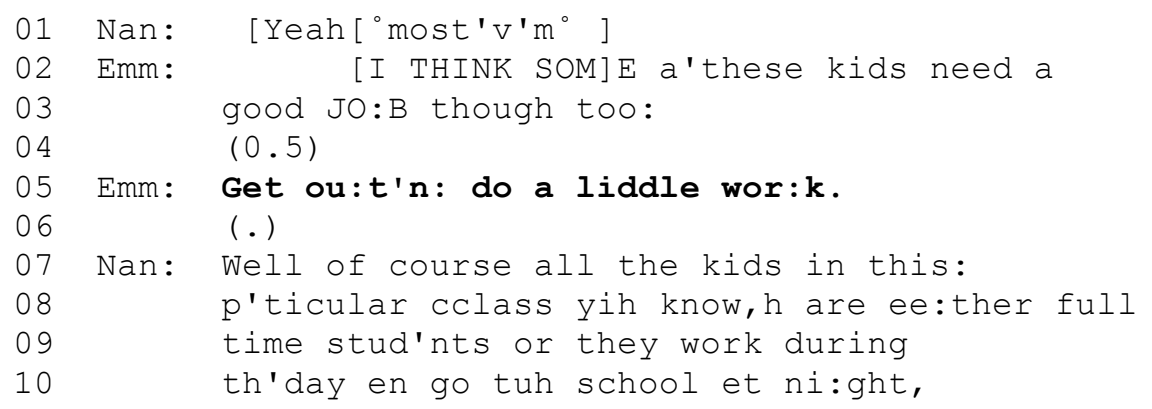

In the above instances (Extracts 1-3), response is pursued using sequence-organizational resources in that the speaker of the initiating action re-issues another version of the action as a complete new turn constructional unit. As we show below, turn-constructional resources can also be exploited to pursue a response. Schegloff (2000) noted that increments - when initiated postgap - can be seen to address "the absence so far of ensuing talk and the possible import of that absence" (see also Ford, Fox, \& Thompson, 2002). This is what can be observed in Extract 4, which instantiates the use of turn-constructional resources for response pursuit. Guy is asking Jon for the phone number of a golf course ("Seacliffs", line 1). When this request is met with 
silence (line 2), he adds a grammatically fitted increment to his possibly complete TCU ("by any chance?" at line 3), thereby displaying an orientation to the possibility that Jon may be about to reject the request (note the use of the "negative polarity marker" "any" Heritage, 2002; Koshik, 2002). By adding an increment to his TCU, the speaker converts an inter-TCU gap into an intraTCU pause, which masks the lack of an answer. In this way, response pursuit is not exposed as the overt business of the talk.

Extract $4: \quad[N B: I: 1: R]$

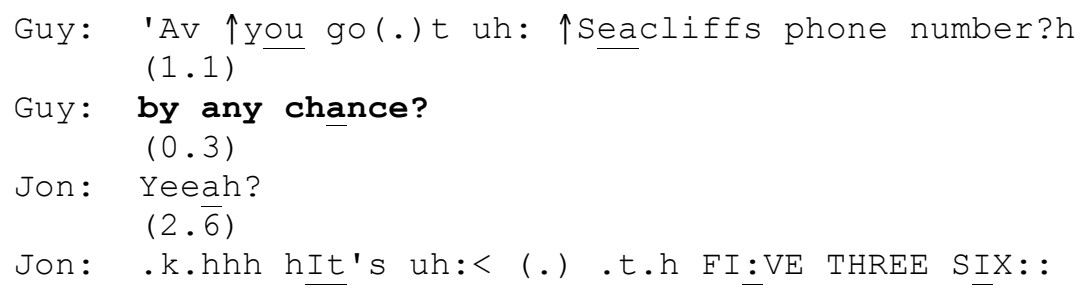

In each of these instances (Extracts 1-4) then, a prior turn reaches possible completion and, when a responsive turn is not immediately forthcoming in a place where speaker transition is relevant, the speaker self-selects to pursue a response. Speakers can use sequenceorganizational resources (as in Extracts 1-3) and turn-constructional resources (as in Extract 4) in pursuing a response. The main finding presented in this paper is that self-initiated self-repairs and especially repairs to indexical expressions - can also be used to pursue a response. While the use of sequence-organizational resources for response pursuit (as in Extracts 1-3) expose the lack of a response as a problem, the use of other practices of response pursuit, such as extending the host TCU with an increment (as in Extract 4) or initiating a transition space repair on its indexical component (as in Extract 5 below, for instance) mask the turn transition problem. As we will see, in proposing - by initiating repair on an indexical reference term - that the problem may have been one of understanding a reference, a speaker can "smuggle in" a pursuit of a "missing" (or in some way problematic) response in a (relatively) covert way. 
Extract 5 provides an initial example of this phenomenon. It comes from the closing segment of a helpline call, in which the call-taker is asking a series of pre-specified monitoring questions - here, the caller's source of information about the service. The call-taker formulates her question (line 1) with the indexical reference term "us" ("And how did you hear about us"). When no response is immediately forthcoming, she repairs the indexical reference, in the transition space, to "the helpline." This serves not only to specify the referent of "us" as "the helpline" (rather than, possibly, the organization which runs it), but also to pursue a response from the caller. (The caller subsequently provides an account for her delayed response: she is trying to recall where she heard about the service.)

\section{Extract 5: [6.] Helpline}

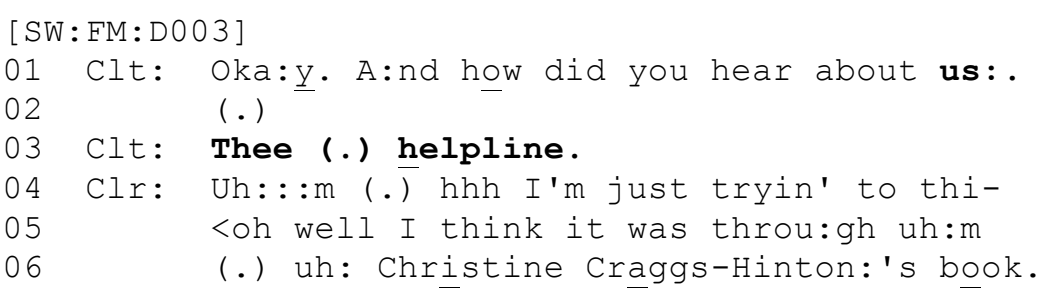

The repair of the indexical, in purporting to clarify the referent, recompletes the speaker's TCU and re-relevances a response from the recipient. Repairs launched in the transition space like this one, or in the third turn (Schegloff, 1992, 1997) (see Extracts 13-14 below), can be seen as covertly pursuing a response by providing the recipient with another opportunity space in which to respond. In what follows, we focus on instances in which, in context, the referent of the indexical is analyzably clear and should, therefore, be accessible to the recipient. In such cases, the repair - while ostensibly dealing with a problem of referential ambiguity - is used to pursue a response. We show, first, some further instances of transition space repairs of indexicals doing pursuit before any response has been produced (i.e. pre-response pursuit). Second, we discuss a range of practices - including repairs of indexicals - for pursuing a response after a response has 
been produced but where that response is treated as insufficient or inadequate (i.e. post-response pursuit). Finally, we briefly show that other forms of repair - beyond repairs of indexical expressions - can also be used in pursuit of a response.

\section{Pre-response pursuit}

In this section, we discuss cases in which a sequence-initiating action (a first pair part) containing an indexical reference is not immediately responded to, and in which, following a gap, its speaker repairs the indexical expression. The provision of the repair solution again makes the answer (turn) relevant on its completion.

Extract 6 is from a child protection helpline call, in which the caller reports problems with her 15-year-old son, who has been drinking and getting into trouble with the police. At lines 1-4, the Child Protection Officer (or CPO) inquires into the details of the son's drinking. She formulates the question using the indexical "it" (at line 3), having immediately before produced a full-form reference ("his drinking" also at line 3). This is a standard locally-subsequent usage of an indexical form that unproblematically locates (in the prior TCU) the locally-initial form "his drinking" as its referent (Schegloff, 1996a).

Extract 6: [148.] The drinking

[HC Boy in Trouble; audio 4:43; $\mathrm{AH}$ ]

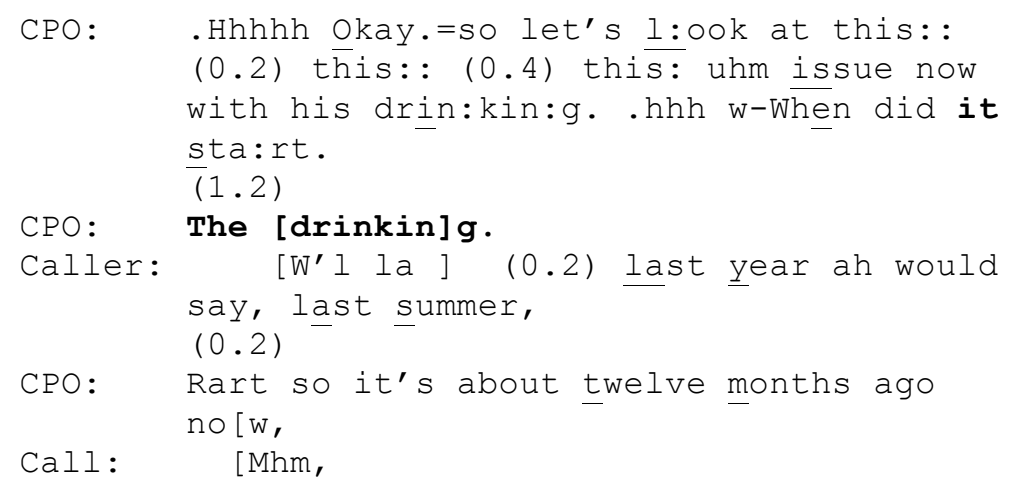


The question (a first pair part) makes a response from the caller conditionally relevant (specifically, some sort of a temporal formulation is due). However, the caller fails to respond and a long silence ensues (at line 5) (cf. Jefferson, 1989). Finally, the CPO pursues a response by repairing the indexical reference "it" in her question at line 3 to the full-form reference, "The drinking." (line 6). The repair solution modifies the locally-initial full-form reference "his drinking" (line 3) to "the drinking" (line 6), which avoids producing a hearable repetition of the trouble source, and is also perhaps a way to objectify or de-personalize this delicate issue. Note that the caller starts answering the question (at line 7) in overlap with the repair solution, in fact, almost simultaneously with the CPO's talk, and before the repair solution can be recognized. This shows that the question - including the indexical reference - was, in fact, understandable to the caller. The delay in providing a response appears to be related to the difficulty in finding an appropriate temporal formulation. Note the epistemic downgrade "I would say" and the recalibration repair (see Lerner et al, this issue) from "last year" to "last summer" (lines 7-8).

In Extract 7, Karen is giving a disparaging review of a TV program (about women warriors) that she and her friend Ben had watched. ("She" in line 2 refers to the narrator of the program.) Following Karen's negative assessment of the language used in the program (at lines 2-4), an agreeing (or disagreeing) response is conditionally relevant from Ben (Pomerantz, 1984a). Ben, however, does not provide any response and (at line 5) a silence develops. Karen chooses to treat the problem in getting uptake as a problem of understanding (rather than a problem of affiliation) and repairs the indexical reference "that" (line 3) in transition space to the full-form reference "girl on girl sex" (line 6). The indexical "that" is unlikely, however, to be unclear to her recipient, given her immediately-preceding use of the full-form reference "girl on 
girl sex" (line 2) in the speaker's report of the offensive language used by the TV program narrator. This suggests that the repair is initiated in order to pursue a response from Ben.

\section{Extract 7: [66.] Sex}

\section{[Land: NE1 ]}

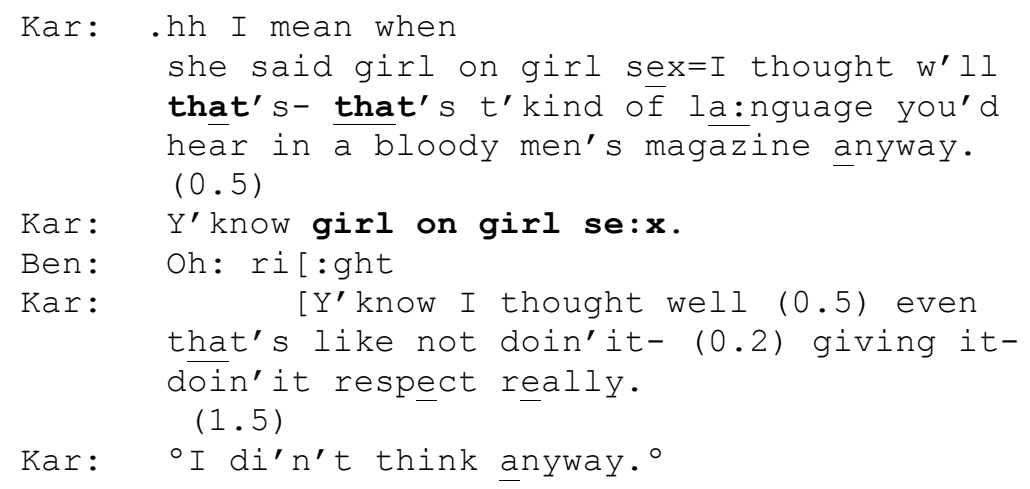

The repair here is initiated with "y'know", which holds Ben responsible for knowing what Karen is talking about (Kitzinger \& Mandelbaum, 2007). Following the repair, Ben responds with "oh ri:ght" (line 6) which treats the repair solution as informative, but does not align or agree with Karen's complaint about the program. As Karen continues with her negative assessment of the program (lines 8-10), Ben still withholds alignment (line 11), and Karen eventually backs down from her position (line 12).

Extract 8 is from a face-to-face conversation (in Russian) between Yana, Greg, and their adult son Gena. They are all about to go on a cruise ship together, but Yana is reluctant (due, primarily, to health concerns). Gena has already told her that it is too late to cancel the trip (data not shown) and is now listing various attractive features of the ship in order to reassure or encourage her about it. At line 1, Gena informs Yana (his primary addressed recipient) that the ship is twice as big as the one they had gone on for another trip. In order to support this claim, Gena goes on to inform Yana that the ship has "a whole huge street of stores" (lines 1-2), using an extreme case formulation (Pomerantz, 1986). In this turn, Gena uses the indexical "there" 
(Russian "tam") to refer to the ship they are about to go on. The place indexical "there" is hearable as a locally subsequent reference to "the ship" in the previous TCU.

Extract 8: [201.] Inside the ship (Russian)

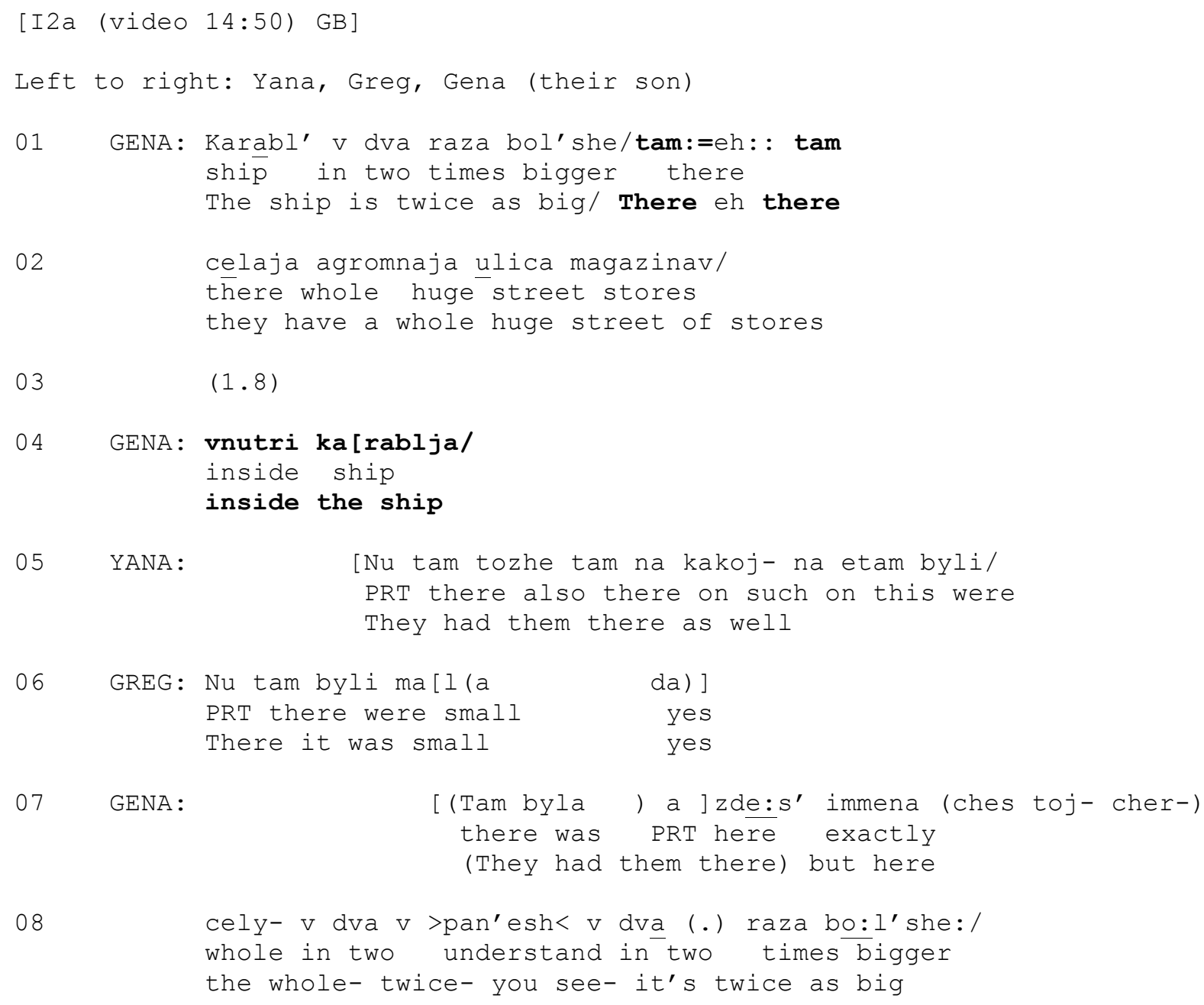

Gena's turn (at lines 1-2) sets up relevancies for a response from Yana. A piece of news has been delivered, which makes relevant a news receipt (e.g., "da?"/“really?") and, possibly, an assessment of the news. Moreover, this piece of information has been provided in the service of a larger interactional project - reassuring or encouraging Yana about the upcoming trip. Within this course of action, then, a response from Yana that would display or claim her having been reassured (or not) is relevant. However, Yana does not respond (see the gap at line 3). During the 
long silence, Gena looks at Yana (who is looking back at him), as if waiting for a response (cf. Stivers \& Rossano, 2010). At the same time (line 3), Greg, the unaddressed recipient of Gena's turn, shifts his gaze from Gena to Yana, which is evidence that he (Greg) expects Yana to provide a response. Gena then takes a turn to repair the indexical "there" (from line 1) to a full form reference "inside the ship" (at line 4). Even though the indexical appears to be unambiguous, the repair treats the lack of uptake as attributable to a problem of understanding (rather than, say, affiliation). By repairing the indexical reference, Gena extends his turn, and, once the repair solution ("inside the ship") is produced, the turn is again response-ready. In this way, repair functions as a covert pursuit of a response from Yana. At line 5, in overlap with the repair solution, Yana takes a turn to respond to Gena. She provides a non-aligning and nonaffilative response (cf. Stivers, 2008) that rejects the newsworthiness of Gena's informing (by claiming that the other ship she was on also had stores) and, thereby, displays not having been reassured.

We have seen then that in Extract 7 and Extract 8, the problem in providing a response was one of disaffiliation or disagreement, while in Extract 6, it was apparently one of "remembering" or of formulating an answer. In repairing an indexical expression, however, the speaker chooses to treat the lack of response as indicative of a problem of understanding a reference (i.e., a problem in turn-construction) rather than a problem of alignment/affiliation. Unlike cases such as Extract 2, in which the speaker modified the character of the initiating action by downgrading it and reversing its preference organization, in the instances we have just shown (Extracts 5-8), the speaker "simply" pursues a response by repairing an indexical to a fullform reference. Pursuing a response by repairing an indexical is a way to assign responsibility for the lack of a response to the producer of the thereby-produced-as trouble source turn. 
Pursuing a response after inadequate uptake

So far we have examined how transition space repair of an indexical expression may provide a (relatively) covert method for pursuing a response when one is not forthcoming. Next, we show that the same practice, repairing an indexical, can also be used to pursue a response after one has been provided, as a third turn repair (Schegloff, 1992, 1997). Faced with a second pair part turn by another, the recipient of that turn can assess it for its adequacy as a response to the initiating action. When the recipient of a second pair part finds it to be in some way inadequate, there is a range of ways in which a "better" (i.e. more fitted or more elaborated) response can be pursued. As shown above with regard to pursuing a response when one is due, but has not yet been provided, pursuit practices can range from relatively overt to relatively covert (Extracts 1-6). Similarly, practices for pursuing a response after an inadequate response can be arrayed on a continuum ranging from those that overtly mark the inadequacy of the response while seeking further elaboration, to those that seek further response but do not overtly make the inadequacy apparent. As Jefferson (1981) notes, the more overtly the inadequacy is marked, the more interactionally-charged the pursuit of a more adequate response may become. For one example of an overt pursuit of a more adequate response, see Extract 9 below, taken from a dinnertime conversation. Dad has been attempting to get his 10-year-old daughter, Cindy, to tell about a school field trip (see, for example, lines 1, 4, and 24/27). When Cindy finally responds with "It was fü:n?” (line 28), Dad first rejects this answer (“No.." line 30) and then negatively assesses it, claiming its inadequacy ("You're gonna h(h)afta do a lot [better 'an tha:t.", line 32). After more prodding from Dad (data not shown), Cindy eventually launches a telling about the trip (line 60). 


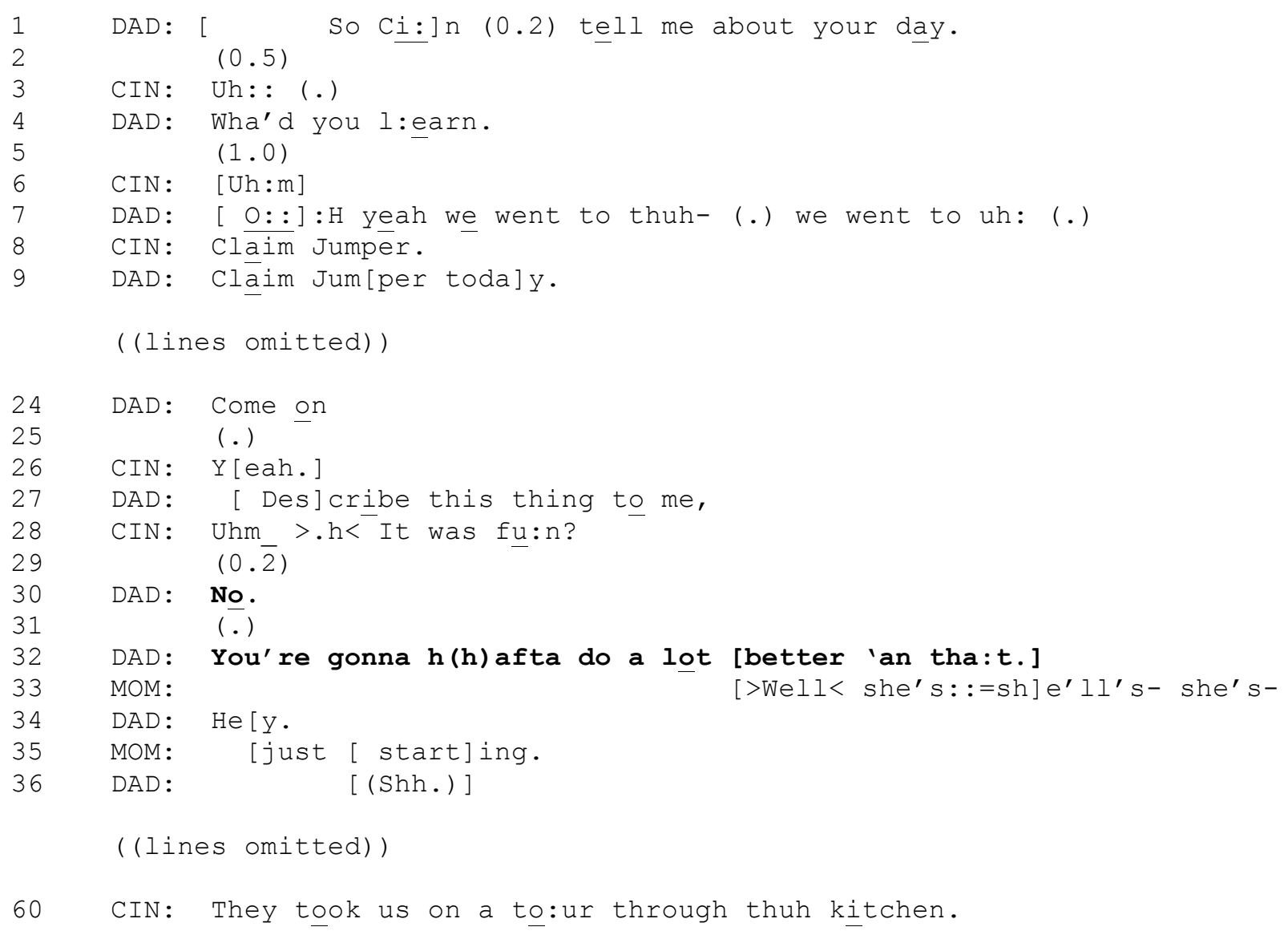

In this case, then, pursuit of a more adequate response is done in such a way as to expose - and criticize - the inadequacy of the provided response.

Less egregious methods for pursuing a "more adequate" response include turnconstructional resources, such as increment elicitors. Lerner (2004) described how one-word TCUs (such as “at" "to," "for," “as," "at," “with," “about,” etc., p. 152), produced by the recipient of a second pair part, can function as "increment elicitors" or "stand-alone prompts." He showed how these prompts treat the prior turn as containing "incipiently projectable but undelivered items" (p. 172). Thus, by targeting what is missing, and prompting its delivery, increment elicitors expose the inadequacy of the provided response and call for the production of that which is missing - as in Extract 10 below (also discussed by Schegloff, 1996b, p. 76): 


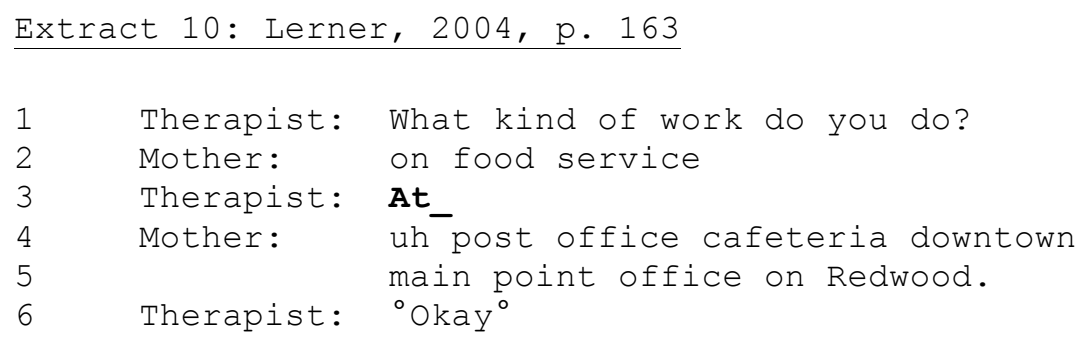

Using prompts with this format shows "not only that more is needed but that more should have been forthcoming" (Lerner, 2004, p. 172). Further, the stand-alone prompt provides the form that the elaboration of the inadequate turn should take: a continuation (and thus an expansion) of the targeted turn. In this way, the increment elicitor indicates explicitly that that targeted turn was not adequate, and provides resources for redressing the inadequacy.

Jefferson (1981) documented two less overt ways of pursuing a response after a response has already been produced: via a response solicitation (such as "right?") and via recompletion of the responded-to turn (with "right" or with an increment). A "Right?" produced after the possible completion of a response may treat the response as inadequate, pursuing further talk. In the following case (Extract 11), Roger produces a minimal “Mm hm” (line 3) in response to Dan's attempt to get him to acknowledge that he has accomplished something during therapy. Jefferson (1981, p. 61) suggested that Dan's next turn, “Ri:ght?” (line 4) recompletes his original turn, prompting a more elaborate response, thus treating the turn to which it is responding as inadequate:

Extract 11: Jefferson, 1981, p. 59 [GTS: V: 71-72]

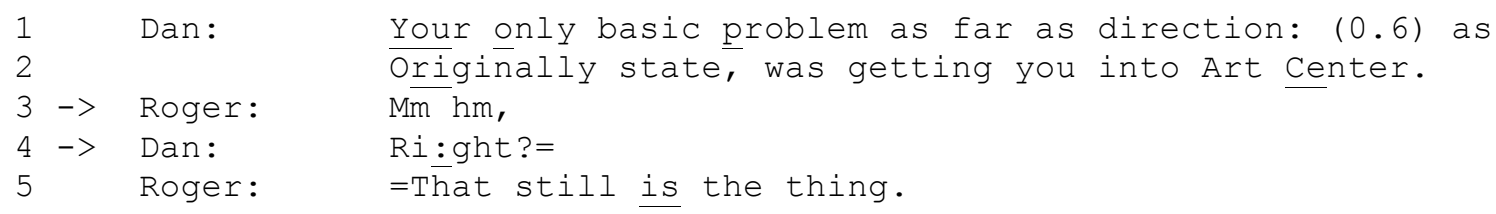

Jefferson noted that there may be some ambiguity as to whether such post-response-completion response solicitation is operating as a turn-exit device, analogous to the tag-positioned response 
solicitation, or is pointing to the inadequacy of the initial response and attempting to occasion some revision (p. 72). In this way, it does not target a specific problem with the prior turn: it informs a recipient that his/her response is inadequate, but provides no further materials from which the recipient might construct an "improved" analysis (p. 75).

Jefferson (1981) also shows that response pursuit via recompletion (a more common and less interactionally-charged alternative to response solicitation) takes the stance that the TCU that appeared to be (or has been produced as) "response-adequate" is, in fact, not - and that some sort of "clarification" is needed (though, of course, more than simply seeking "clarification" may be accomplished when further response is pursued in this way), as Extract 12 indicates:

Extract 12: Jefferson (1981, p. 77)

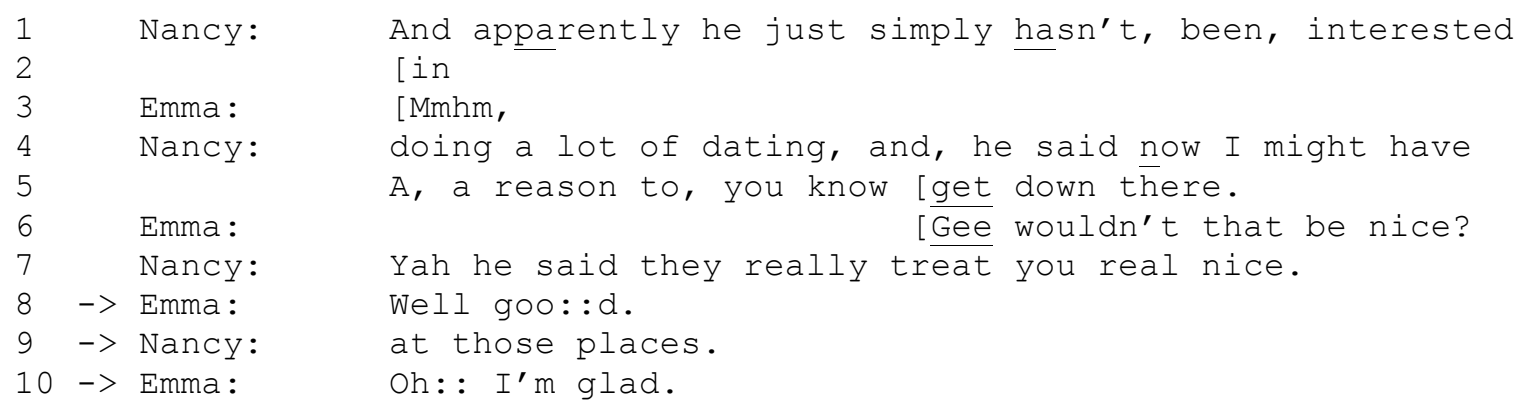

Nancy's recompletion of her turn at line 9 (via an incremental extension) re-relevances a response from Emma by adjusting slightly the initial TCU, without going on record as seeking a further (and more "adequate") response. Similarly, as we show below, repairing an indexical, (sometimes through the addition of an increment), recompletes the turn that received the apparently inadequate response, re-relevancing a response, by treating the indexical expression as a possible trouble source underpinning the inadequacy of the response. 


\section{Post-response pursuit of response by repairing an indexical}

In the following we show that repairing an indexical provides a covert method for pursuing a more adequate response. Extract 13 takes place at a dinner between two couples Vivian and Shane, and Michael and Nancy - in California, on the warm West Coast of the United States. Shane and Vivian report on extreme cold weather on the East Coast and its impact (lines 1-17). Throughout the report, uptake from Nancy and Michael is somewhat minimal: eye brow flashes from Michael after the first bad news delivery ("Cars ih stra:nded 'bout thirdy sump'n people'v die:d," at lines 16-17) and again after Shane recompletes the turn with "because of that" (line 22). However, note that in line 20, Nancy produces a verbal show of surprise, "Wo:w." (Wilkinson \& Kitzinger, 2006). At this point, then, Shane's announcement about the stranded cars and the large number of deaths has received a minimal response from Michael, and a fitted response from Nancy (albeit a somewhat delayed one). However after a (0.4) second gap (line 21), Shane extends his turn (from lines 16-17) with "Becuz a'that" (line 22), addressed to Michael via gaze, recompleting it by apparently making more explicit the connection between the deaths and the snow as the reason for the deaths. His extension of his turn suggests that the eyebrow flash Michael has produced in line 18 may not be a sufficient response for this news, and that he may be seeking Michael's uptake in addition to (or instead of) Nancy's. It may be that the minimal response embodied in the eyebrow flash is not calibrated to the "extreme" character of the news; and/or that it is specifically Michael from whom Shane is seeking a response (insofar as the recompletion of the turn disattends Nancy's response). The recompletion that is apparently designed to pursue a fuller response from Michael elicits the same minimal response (another eyebrow flash from Michael at line 23). After another gap (line 24), and an agreement or confirmation from Vivian (line 25), Shane again recompletes his turn (line 26), this 
time expanding his turn (from line 22) by replacing the indexical "that" with the full form reference "the weather". The pre-framing of the repaired indexical with "c'ss" (line 26) makes it hearable as replacing "that" (in line 22). In line 27, Vivian begins a new activity, and no additional response from Michael is produced in response to Shane's pursuit.

\section{Extract 13: [62] The weather}

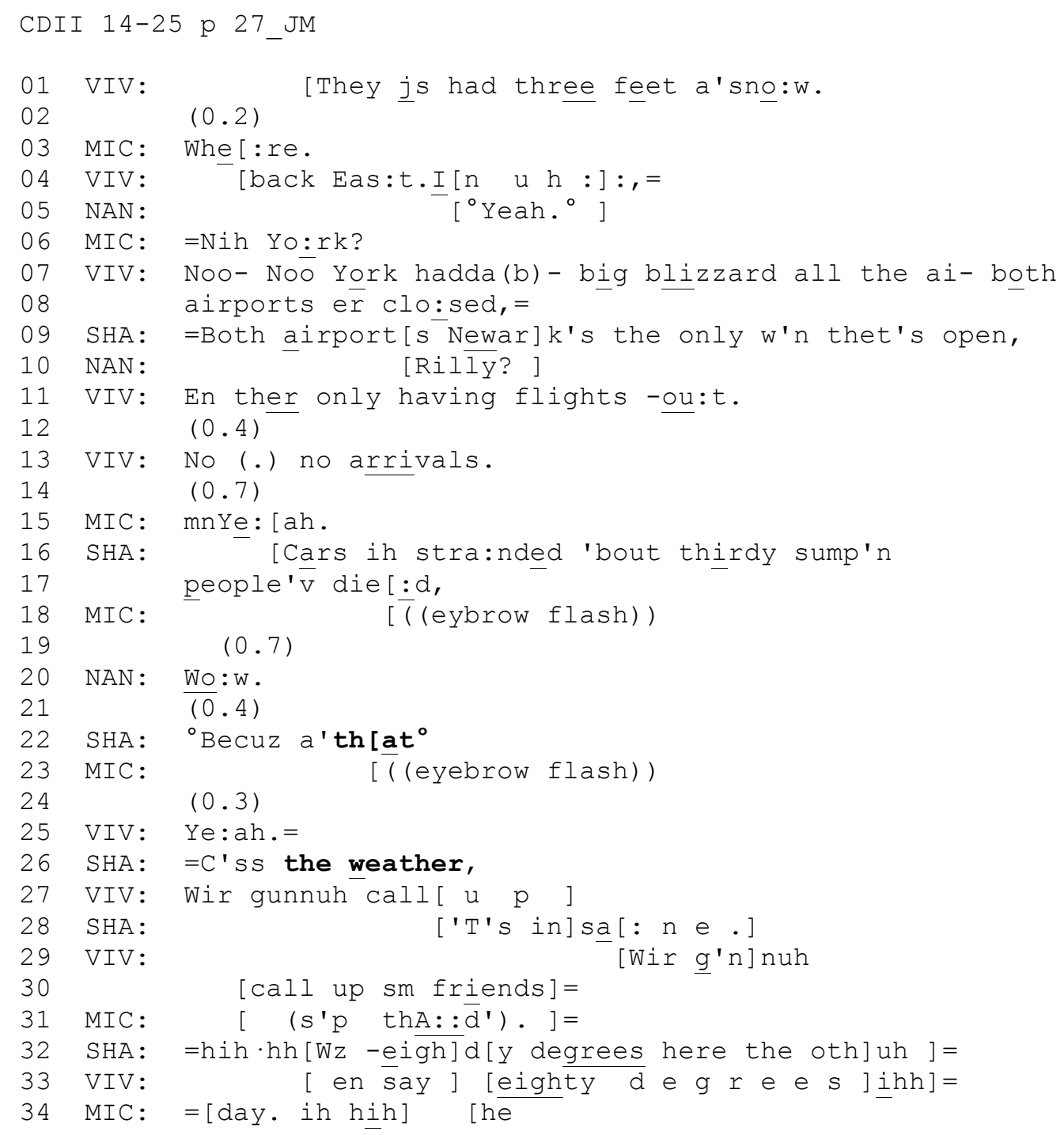

This instance indicates that there are times when speakers may not want to go on record as pursuing a response. After Shane has received a response from Nancy (one member of the recipient party), he nonetheless pursues a response from the other member, Michael (cf. Lerner, 
1993). This produces an interesting by-product of segregating Nancy and Michael as recipients of Shane's report, rather than treating Nancy's "Wow" (line 20) as a response on behalf of the recipient party, but provides a covert method for doing so.

Extract 14 is from a face-to-face conversation (in Russian) involving a grandmother and her visiting granddaughter Lena. Lena has already eaten and now the grandmother is having coffee with a sandwich. Just prior to this extract, the grandmother was explaining what she had on her sandwich. At line 3, the grandmother offers Lena a sandwich by saying " $\{$ You $\}$ want \{it\}?" while pointing to the plate where her sandwich is placed. Note that in Russian, one does not need to explicitly state what is being offered in this context. In grammatical terms, the Russian verb "want" does not need to have the direct object slot filled if it is inferable from context. Referring to the sandwich is accomplished via the pointing gesture, without the use of an overt/explicit referring expression (cf. Bolden \& Guimaraes, this issue). In other words, in Russian, line 3 constitutes a possibly complete turn constructional unit - an offer of a sandwich. The offer makes an acceptance/rejection conditionally relevant from the addressee (Schegloff, 2007). Lena does not immediately respond (see the gap at line 4), which indicates the possibility that the offer may be rejected. Then (at line 5), she goes on to respond non-vocally, with a lateral headshake that conveys her rejection (line 5). Rejection is ordinarily ${ }^{\mathrm{ii}}$ a dispreferred response to an offer, and dispreferred (and disaffiliative) responses are accountable actions, typically (or even normatively) accompanied by accounts or explanations (Heritage, 1984; Robinson \& Bolden, 2010). While the headshake accomplishes the action of rejecting, it is a minimalistic and thus perhaps insufficient response.

Extract 14: [203.] Sandwich (Russian)

[I5a (video 56:50) GB]

((GRM puts the sandwich down on her plate)) 


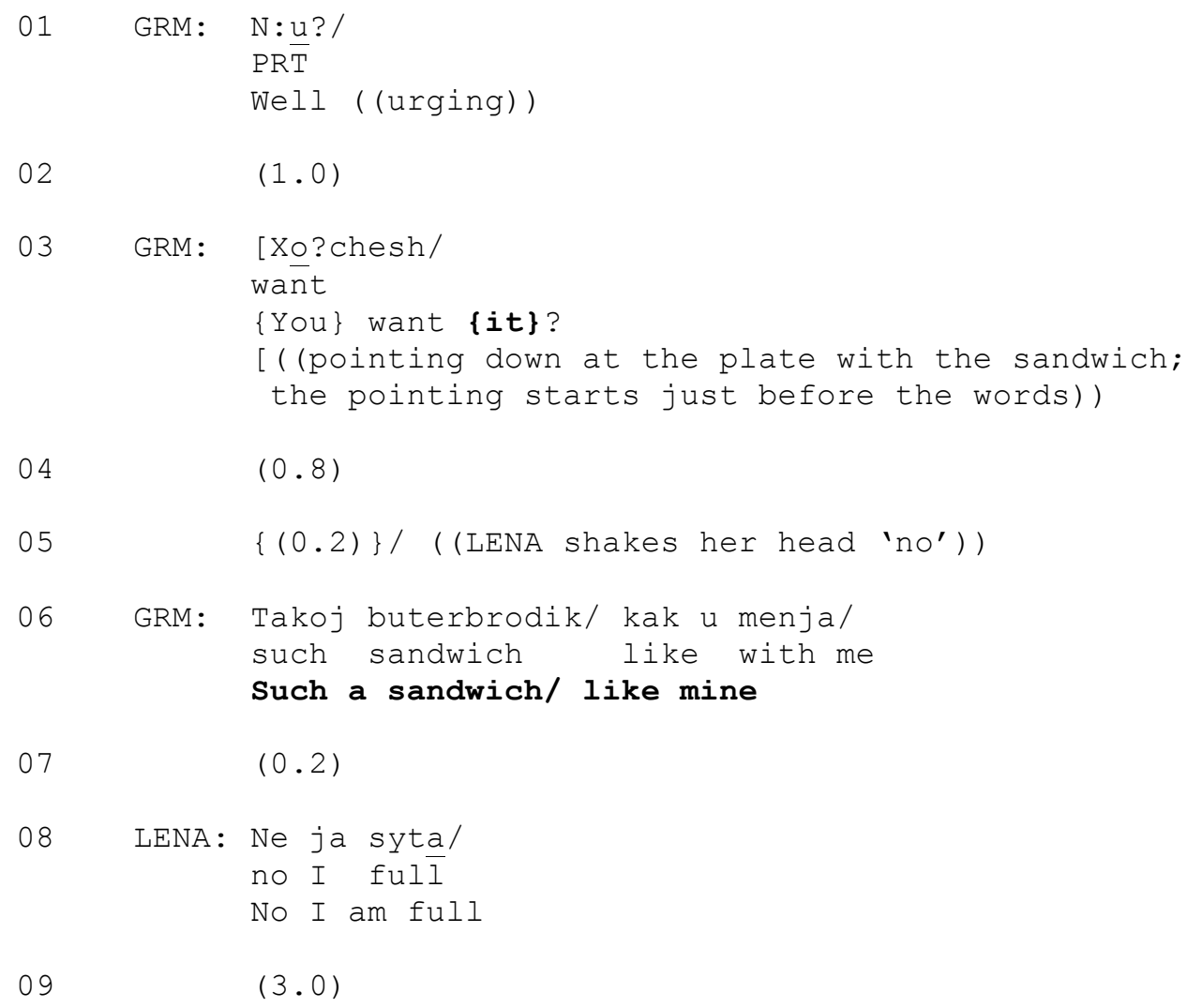

Having seen the headshake, the grandmother takes her turn again and (at line 6) explicates what is being offered: "such a sandwich, like mine". This constitutes a grammatically fitted continuation of the prior TCU, translatable now as: "You want a sandwich, like mine?" (cf. Bolden \& Guimaraes, this issue). With this increment to the preceding TCU, the grandmother makes explicit what she had meant by her offer, even though it was understandable - and, in fact, understood by Lena, as her rejection shows. In this sequential environment - after the offer had been rejected non-vocally - the added explication (at line 6) appears to be a tactic for pursuing a more adequate response: either a fuller response (with an account) or possibly a different response (acceptance). Unlike some other types of post-response pursuits (e.g., Extracts 9 and 10), pursuing a response in this way - via a grammatically fitted increment that simply recompletes the host TCU - disattends the provided response and re-insists that a response should be provided (cf. Jefferson, 1981). Here, the unpacking of an indexical is a technique for re- 
relevancing a response to a rejected offer without going on record as re-doing the offer (and thus avoiding being seen as pushy).

In pursuing further response after a response has been provided, repairing an indexical may provide a method for doing so that is less interactionally-charged than overtly pursuing a response. The producer of the first pair part takes responsibility for producing a full form version of the indexical in response to a thereby-treated-as inadequate second pair part from another party. In doing so, the speaker re-issues an opportunity to respond without modifying the initiating action but simply elaborating the reference. In comparison to other methods of response pursuit that use sequence-organizational resources (e.g., whole new TCUs, as in Extract 9) or turn-constructional resources (e.g., increment elicitors or response solicitations, as in Extracts 10 and 11), repairing an indexical reference is a relatively covert way of pursuing a (more) adequate response. It does not expose a problem with the initial response but simply disattends it. Further, in producing an "improved" version of the initial turn (with a full-form reference instead of an indexical), the producer of the initiating action treats it as his or her "fault" that an inadequate response was produced - indicating (by repairing the indexical) that there might have been a problem that resulted in the initiating action not being fully understandable.

Other forms of repair used for pursuing a response

The practice of using repair to pursue a response is not limited to repairing indexicals. When the affordances of the turn-so-far in its sequence-so-far allow for it, other forms of repair can also be employed to accomplish pursuit, as illustrated by the following two cases.

Extract 15 is taken from a face-to-face conversation between three college students who are heavily involved in college athletics as members of the gymnastics team. They have been 
discussing a women's basketball team at another university. Following a short lull in the conversation (not shown), Angela inquires if Cathy has heard a piece of news about "the team" (lines 1-2). Following a two-second silence (line 3), Angela repairs her prior turn by replacing "the team" with "women's basketball" (line 4), specifying which team is being referred to. This transition space repair re-relevances a response from the addressee.

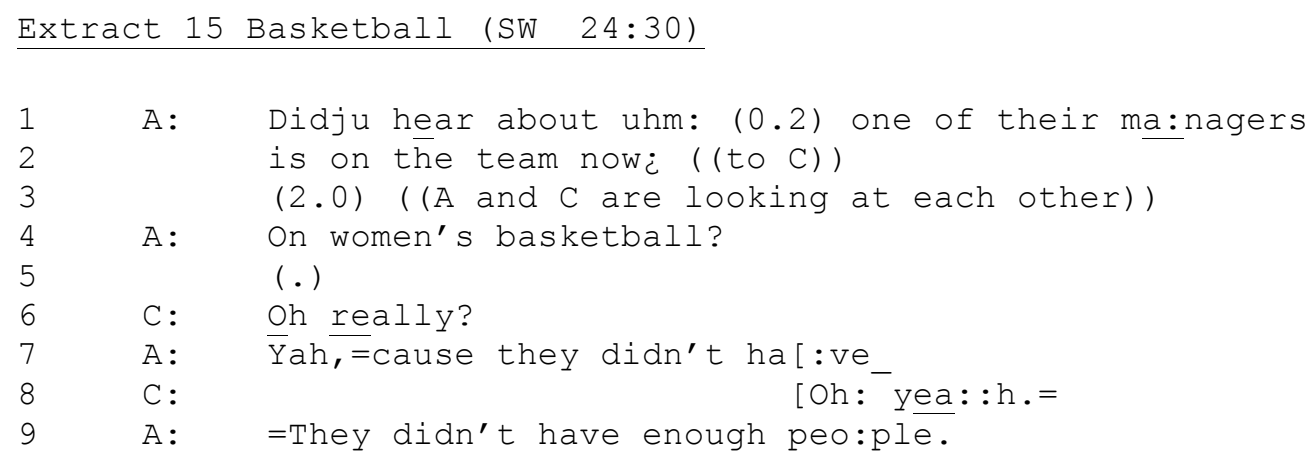

By repairing her initiating action in this way, the speaker treats the lack of response as indicative of the recipient's problem of understanding. This diagnosis turns out to be correct, as, immediately following the repair, Cathy provides a conditionally relevant response ("Oh really?" at line 6) that treats Angela's initiating action as announcing news.

Extract 16 is taken from an interview with Lynndie England (LE), a former US Army personnel, who had been convicted of torturing and abusing prisoners of war. Here, the interviewer (IR) is asking about an incident in which England was photographed with naked detainees. The interviewer uses both repair resources (line 8 ) and turn-constructional resources (line 10) in pursuit of a response.

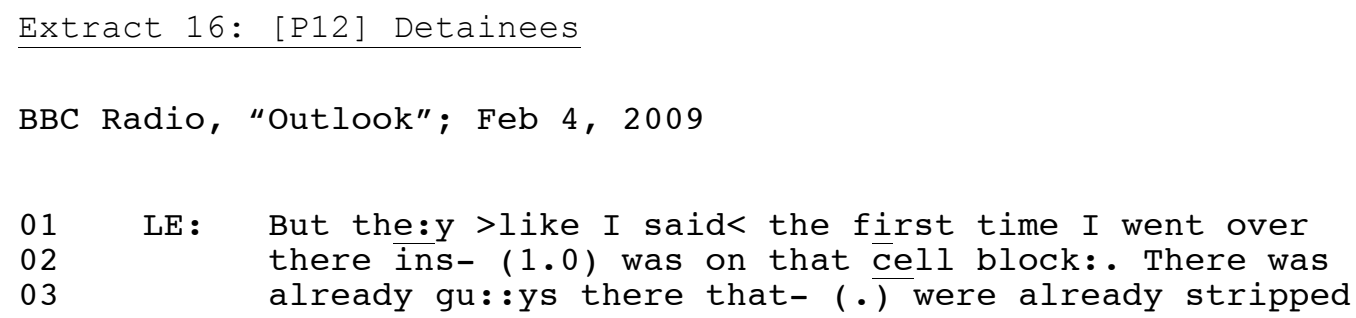




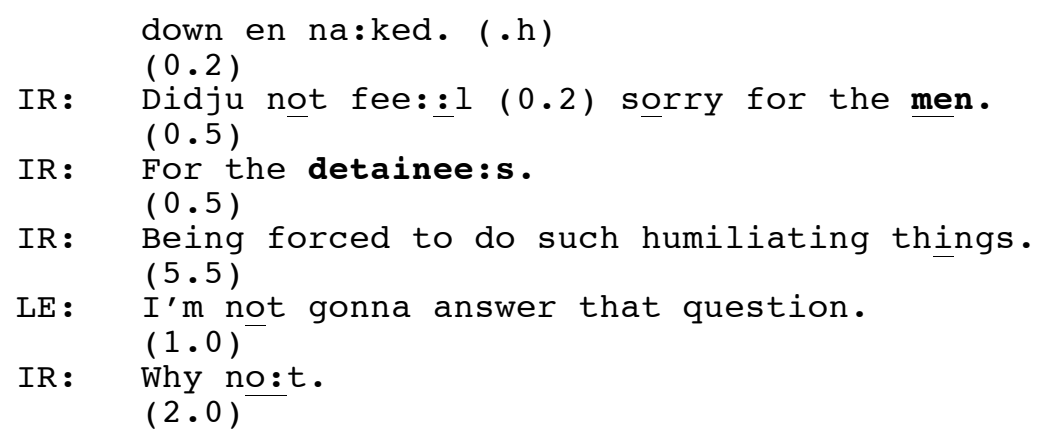

When the interviewer's question (line 6) is not responded to (line 7), the interviewer pursues a response by treating the person reference "the men" (at line 6) as a trouble source and replacing it with "the detainee:s" (line 8). The repair replaces the rather generic reference "the men" with a more granular, topic-specific categorical reference "the detainees," highlighting the men's position in relation to the interviewee (see Lerner et al, this issue, for a fuller treatment of granularity recalibration repair). When England still fails to respond (line 9), the interviewer again pursues a response, this time by adding an incremental extension (line 10) to her TCU (cf. Bolden \& Guimaraes, this issue; Schegloff, 2000; Ford, Fox, \& Thompson, 2002). After an exceptionally long silence (line 11), England explicitly refuses to answer the question (line 12). We can note that although pursuit of a response is manifestly the business of the interviewer's talk, the resources used in this pursuit (i.e. granularity recalibration repair and an incremental extension of the host TCU) do not explicitly expose the lack of a response as the addressee's problem (cf. Extract 1). In both of these extracts, then, the speaker of the initiating action, by initiating repair on it, treats her own prior talk as apparently inadequate and does not expose the lack of a response as a problem.

The extracts analyzed here suggest that, not only repair on indexical expressions, but selfinitiated self-repair more generally can provide a rather covert resource for pursuing a response. Self-initiated self-repair treats the speaker's (or self's) prior utterance as possibly problematic 
and, in doing so, suggests that resolution of the possible problem could provide for the not-yetproduced but called-for response from the recipient.

\section{Conclusions}

As the papers in this volume show, repairs of indexicals may be designed to address the kind of problems that indexical expressions themselves can result in - indeterminate or possibly unclear reference, for instance. However, this repair technology can be exploited in the service of accomplishing other actions. Here we have shown how it can be used in the service of pursuing a response - either because a response is relevantly missing, or because a response is judged as in some way "inadequate." We have shown that speakers have a variety of types of resources for pursuing a response, including sequence-organizational and turn-constructional resources. We have focused here on a third type of resource: a repair-based resource, specifically replacement of an indexical with a full-form reference.

We have shown that speakers have resources to pursue a response overtly, but that they can also pursue a response covertly, by repairing an indexical. Initiating repair on an indexical expression in transition space claims that the problem may be one of understanding a reference, and by repairing it, the speaker makes available another opportunity for a response, without making response pursuit the overt business of the talk. Likewise, initiating repair on an indexical expression (in the third turn) covertly treats the provided response as in some way inadequate, while avoiding going on record as doing so.

In sum, we have shown that by repairing an indexical in the transition space, or after a possibly inadequate response, the speaker treats a transition problem - that is lack of uptake, or inadequate uptake from the recipient - as a turn-construction problem. The speaker uses an indexical repair as an opportunity to recomplete their turn, thereby re-relevancing a response. By 
ostensibly dealing with problems of reference, repairs on indexicals provide a covert method for managing other more interactionally-charged issues, such as upcoming disagreement or other forms of misalignment between interlocutors. These repairs of indexicals exploit the technology of repair in the service of another action: here, pursuit. 


\section{References}

Davidson, J. (1984). Subsequent versions of invitations, offers, requests, and proposals dealing with potential or actual rejection. In J. M. Atkinson \& J. Heritage (Eds.), Structures of Social Action (pp. 102-128). Cambridge: Cambridge University Press.

Ford, C. E., Fox, B. A., \& Thompson, S. A. (2002). Constituency and the grammar of turn increments. In C. E. Ford, B. A. Fox \& S. A. Thompson (Eds.), The language of turn and sequence (pp. 14-38). Oxford: Oxford University Press.

Heritage, J. (1984). Garfinkel and ethnomethodology. New York: Polity Press.

Heritage, J. (2002). The limits of questioning: negative interrogatives and hostile question content. Journal of Pragmatics, 34, 1427-1446.

Jefferson, G. (1981). The abominable $n e$ ? An exploration of post-response pursuit of response. In P. Shroder (Ed.), Sprache der gegenwaart (pp. 53-88). Düsseldorf: Pedagogischer Verlag Schwann.

Jefferson, G. (1989). Preliminary notes on a possible metric which provides for a 'standard maximum' silences of approximately one second in conversation. In D. Roger \& P. Bull (Eds.), Conversation: An interdisciplinary perspective (pp. 166-196). Clevedon: Multilingual Matters.

Kitzinger, C., \& Mandelbaum, J. S. (2007). 'You know' repair initiations in same-turn selfinitiated repair in the domain of word selection. Paper presented at the at the annual convention of the National Communication Association, Chicago, IL.

Koshik, I. (2002). A conversation analytic study of yes/no questions which convey reversed polarity assertions. Journal of Pragmatics, 34, 1851-1877. 
Lerner, G. H. (1993). Collectivities in action: establishing the relevance of conjoined participation in conversation. Text, 13, 213-245.

Lerner, G. H. (2004). On the place of linguistic resources in the organization of talk-ininteraction: Grammar as action in prompting a speaker to elaborate. Research on Language and Social Interaction, 37, 154-184.

Oh, S.-Y. (2005). English zero anaphora as an interactional resource. Research on Language and Social Interaction, 38, 267-302.

Pomerantz, A. (1984a). Agreeing and disagreeing with assessments: some features of preferred/dispreferred turn shapes. In J. M. Atkinson \& J. Heritage (Eds.), Structures of social action: Studies in conversation analysis (pp. 57-101). New York: Cambridge University Press.

Pomerantz, A. (1984b). Pursuing a response. In J. M. Atkinson \& J. Heritage (Eds.), Structures of social action (pp. 152-164). Cambridge: Cambridge University Press.

Pomerantz, A. (1986). Extreme case formulations: A way of legitimizing claims. Human Studies, 9, 219-229.

Robinson, J. D., \& Bolden, G. B. (2010). Preference organization of sequence-initiating actions: The case of explicit account solicitations. Discourse Studies, 12, 501-533.

Sacks, H. (1987). On the preferences for agreement and contiguity in sequences in conversation. In G. Button \& J. R. E. Lee (Eds.), Talk and social organization (pp. 54-69). Philadelphia: Multilingual Matters.

Sacks, H., Schegloff, E. A., \& Jefferson, G. (1974). A simplest systematics for the organization of turn-taking for conversation. Language, 50, 696-735. 
Schegloff, E. A. (1992). Repair after next turn: the last structurally provided defense of intersubjectivity in conversation. American Journal of Sociology, 97, 1295-1345.

Schegloff, E. A. (1996a). Some practices for referring to persons in talk-in-interaction: a partial sketch of a systematics. In B. A. Fox (Ed.), Studies in Anaphora (pp. 437-485). Philadelphia: John Benjamins Publishing.

Schegloff, E. A. (1996b). Turn organization: one intersection of grammar and interaction. In E. Ochs, E. A. Schegloff \& S. A. Thompson (Eds.), Interaction and grammar (pp. 52-133). Cambridge: Cambridge University Press.

Schegloff, E. A. (1997). Third turn repair. In G. R. Guy, C. Feagin, D. Schiffrin \& J. Baugh (Eds.), Towards a Social Science of Language (Vol. 2, pp. 31-40). Philadelphia: Benjamins Publishing.

Schegloff, E. A. (2000, November). On turns' possible completion, more or less: Increments and trail-offs. Paper presented at the 2000 Annual Conference of the National Communication Association, Seattle, Washington.

Schegloff, E. A. (2007). Sequence organization in interaction: A primer in conversation analysis. Cambridge: Cambridge University Press.

Stivers, T. (2008). Stance, alignment, and affiliation during storytelling: When nodding is a token of affiliation. Research on Language and Social Interaction, 41, 31-57.

Stivers, T., \& Rossano, F. (2010). Mobilizing response. Research on Language \& Social Interaction, 43, 3-31.

Wilkinson, S., \& Kitzinger, C. (2006). Surprise as an interactional achievement: Reaction tokens in conversation. Social Psychology Quarterly, 69, 150-182. 


\section{Footnotes}

${ }^{i}$ Note that the second proffered assessment deploys "zero anaphora" to refer to the sentential subject ("some of these kids"), which is a practice for marking the current TCU as a second saying (Oh, 2005).

ii Some offers ("pro-forma" offers) are designed to be rejected (Schegloff, 2007, p. 60), however there is no evidence the grandmother is doing it here. And yet, offers of food by a host might be ritualistically rejected by a guest on the first offering so that they can be then re-offered and possibly accepted. The ritualistic nature of the first (possibly pro-forma) rejection sets up an expectation for a second offer. Offerers may be oriented to the possibility that the recipient may take it that the offer is to be rejected (at first), and, thus, may issue subsequent offers to counteract the supposition that the offer was a pro-forma one. 